https://helda.helsinki.fi

Tattoos among Professional ATP and WTA Tennis Players

\title{
Kluger, Nicolas
}

2018

Kluger , N 2018 , ' Tattoos among Professional ATP and WTA Tennis Players ' , Dermatology , vol. 234 , no. 5-6 , pp. 229-231 . https://doi.org/10.1159/000493504

http://hdl.handle.net/10138/272979

https://doi.org/10.1159/000493504

unspecified

publishedVersion

Downloaded from Helda, University of Helsinki institutional repository.

This is an electronic reprint of the original article.

This reprint may differ from the original in pagination and typographic detail.

Please cite the original version. 
Dermatology 2018;234:229-231

DOI: $10.1159 / 000493504$

\section{Tattoos among Professional ATP and WTA Tennis Players}

Nicolas Kluger ${ }^{a, b}$

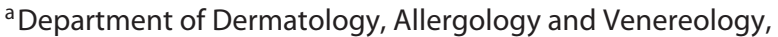
University of Helsinki and Helsinki University Central Hospital, Helsinki, Finland; "battoo" Consultation, Department of Dermatology, Bichat-Claude Bernard Hospital, Assistance Publique-Hôpitaux de Paris, Paris, France

\section{Keywords}

Sport $\cdot$ Tattoo $\cdot$ Tattooing $\cdot$ Tennis

\section{Background}

Currently $10-30 \%$ of the general population has tattoos [1]. The trend of tattooing is also observed among athletes [2]. Media coverage about "sports stars" and their tattoos gives the impression that tattoos are frequent $[2,3]$. However, the prevalence of tattoos among athletes has not been assessed in detail. Tattoos appear to be frequent in team sports, such as football or basketball [4]. We found that $34 \%$ of the football players had visible tattoos during the FIFA World Cup in Russia in 2018 [Kluger and Samimi, pers. data, under submission]. Little is known about individual sports. As tennis is the most popular individual sport in Europe (26 million players) [5], we assessed the prevalence and the characteristics of tattoos among professional tennis players.

\section{Methods}

We reviewed the presence of visible tattoos among the top 100 tennis players of the men's ATP and women's WTA rankings as of July 16, 2018 (200 players). Gender, age, nationality, ranking and points were collected from the official ATP and WTA websites. To collect players' tattoos, we used the Getty Images website [5], a stock photo agency, which supplies stock images with an archive of 80 million still images. We used the following key words on the website's search bar: "Tennis 2018 + Player first name and surname." We noted visible tattoos that could be seen on the field during the game (upper arms, legs, head and neck). Tattoos of the trunk (under the shirt) and permanent makeup were excluded. Size, number, design and meaning of the tattoos were not analyzed.

Statistical analysis was conducted with SPSS Statistics 22 (IBM). Players' characteristics are presented as means and standard deviations or median and ranges for continuous variables and as frequencies and proportions for categorical variables. Data were compared using Fisher's exact test for categorical variables and Kruskal-Wallis nonparametric tests for continuous variables. The statistical significance threshold was set at $p<0.05$.

\section{Results}

Eighteen players (9\%) had 1 visible tattoo or more (Table 1): 11 women $(11 \%)$ and 7 men $(7 \%, p>0.05)$. Among men, all were tattooed only on the upper limbs. Two had tattoos on both arms. Three players had tattoos that were hardly visible as they were almost hidden by the shirt sleeves. All the players were right-handed, and $85 \%$ had tattoos on the right arm. The mean ages between the tattooed and the nontattooed men players were similar (27.8 and 27.4 years, respectively). The tattooed players were almost all ranked among the top 50 (from 15 to 52 , mean $35 \pm 17$ ). The median number of points was also higher among the tattooed players (1,160 vs. 920 points).

Among women, all had tattoos on the upper limbs, but 3 players had additional tattoos on the neck $(n=2,18 \%)$ and the thigh ( $n=1,9 \%)$. All but one were right-handed. Among them, only $40 \%$ had tattoos on the right arm. The mean age, ranking and median points were similar between tattooed and nontattooed women.

\section{Discussion}

The prevalence of tattoos among the top 100 players in July 2018 was $9 \%$. There was a higher prevalence among women. Media articles confirm that tattoos are more popular among tennis women [6]. These figures remain however lower compared to the general population in the same age group (20-40 years, approx. $30 \%$ ) [1] or football players (34\%). Tennis players usually displayed small and discrete tattoos that may be hidden either under the wrist band or the tee-shirt sleeve. This is a notable difference to the extensive and overexposed tattoos of football or basketball players for instance. Only 1 woman player had extensive tattooed sleeves. All the players had at least a tattoo on the arm. Men tended to have tattoos on their dominant hand (that serves and strikes forehands), while women tended to have it on the opposite arm. This choice could be either fortuitous or deliberate. Tennis players may get tattooed for various reasons that are personal [7]. But, tattoos do bolster the ego [8] and can be associated with aggressiveness [9]. Tattooed men had a better median ranking and higher points, however without statistical significance. No difference was observed for women. Association naturally does not mean causality, but tattoos might be a sign of higher aggressiveness and competitiveness on the tennis field for men.

The striking low prevalence of tattoos among professional tennis players might be explained by various factors: personal sociocultural background, as tennis is traditionally associated with upper classes; player's environment and different body image in tennis compared to other sports (football, basketball). Tennis is characterized by a sociocultural dress code, a high degree of "con-

\section{KARGER}

(C) 2018 S. Karger AG, Basel

E-Mail karger@karger.com

www.karger.com/drm
Nicolas Kluger, $\mathrm{MD}, \mathrm{PhD}$

Department of Dermatology, Skin and Allergies Hospital

Helsinki University Central Hospital, Meilahdentie 2, PO Box 160

FI-00029 HUS, Helsinki (Finland)

E-Mail nicolas.kluger@hus.fi 
Table 1. Characteristics of tattooed ATP and WTA top 100 players

\begin{tabular}{|c|c|c|c|c|c|}
\hline & \multicolumn{2}{|c|}{ Professional men $(n=100)$} & \multicolumn{2}{|c|}{ Professional women $(n=100)$} & $p<0.05$ \\
\hline Mean age (SD), years & $27.4(4.5)$ & & $26.1(4.0)$ & & ns \\
\hline Median age, years & 28 & & 26 & & - \\
\hline \multicolumn{6}{|l|}{ Tattoos } \\
\hline Tattooed players & $7(7)$ & & $11(11)$ & & ns \\
\hline Mean age (SD), years & $27.8(4.7)$ & & $27(4.4)$ & & ns \\
\hline Median age, years & 29 & & 27 & & \\
\hline \multicolumn{6}{|l|}{ Continent of origin } \\
\hline Europe & $5(71)$ & & $9(82)$ & & \\
\hline Australia & $2(29)$ & & - & & \\
\hline North America & - & & $2(18)$ & & \\
\hline Upper limb & $7(100)$ & & $11(100)$ & & ns \\
\hline Arm & $3(43)$ & & $2^{1}(18)$ & & ns \\
\hline Forearm & $4(57)$ & & $5(45)$ & & ns \\
\hline Wrist & $1(14)$ & & $7(64)$ & & 0.04 \\
\hline Finger/hand & $1(14)$ & & $1(9)$ & & ns \\
\hline Lower limb & - & & $1(9)$ & & - \\
\hline Head and neck & - & & $2(18)$ & & - \\
\hline \multicolumn{6}{|l|}{ Handiness } \\
\hline Right-handed & $7(100)$ & & $10(91)$ & & ns \\
\hline Tattoo(s) on the right arm & $6(85)$ & & $4(40)$ & & $\mathrm{ns}$ \\
\hline ATP/WTA ranking & Tattooed & Nontattooed & Tattooed & Nontattooed & \multirow{3}{*}{$\mathrm{ns}^{2}$} \\
\hline Mean (SD) & $34.9(16.6)$ & $51.6(29.5)$ & $50.6(34.8)$ & $50.5(28.4)$ & \\
\hline Median (ranges) & $37(15-52)$ & $54(1-100)$ & $57(5-95)$ & $50(1-100)$ & \\
\hline ATP/WTA points & Tattooed & Nontattooed & Tattooed & Nontattooed & \multirow{3}{*}{$\mathrm{ns}^{2}$} \\
\hline Mean (SD) & $1,400(482)$ & $1,499(1,468)$ & $1,938(1,681)$ & $1,617(1,369)$ & \\
\hline Median (ranges) & $1,160(2,030-966)$ & $920(9,310-578)$ & $976(5,020-702)$ & $1,156(7,571-643)$ & \\
\hline
\end{tabular}

ns, not significant; SD, standard deviation. ${ }^{1}$ Including 1 player with a visible shoulder tattoo. ${ }^{2}$ Comparison between tattooed and nontattooed players within the same gender.

trol" (7 referees per game) and therefore a strong sense of "etiquette." For instance, rules in Wimbledon require that all the players play all white [10]. However, tattoos are not forbidden [11].

As an individual sport, tennis players do not get daily emulation or stimulation with other team members. A tattooed environment (friends or family, or here team members) is usually a strong factor predicting tattooing [1]. Lastly, a busy competition agenda all year long may not allow players to get tattooed as it implies a tattoo healing and aftercare period for several weeks that could disturb trainings and competitions.

Limitations of our study include that we collected only visible tattoos and may have missed tattoos of the chest, back or feet. We reviewed the top 100 players at a given time. As the ranking is updated weekly, additional tattooed players of the circuits such as Bethanie Mattek-Sands or Stanislas Wawrinka were not in the top 100 at the time of inclusion and therefore not assessed.

To conclude, apart exceptions $[6,11]$, tennis professional players do not have a culture of tattoos, possibly for historical and cultural reasons. The heavy yearly competition agenda and lack of peer motivation may be additional factors. Tattoos are not frequent in every sport.

Key Message

Tattooing is rare among tennis players, most likely for sociocultural reasons.

Disclosure Statement

The author declares no conflict of interest.

\section{References}

1 Kluger N. Epidemiology of tattoos in industrialized countries. Curr Probl Dermatol. 2015;48:6-20.

2 Athletes and their tattoos: From A-Z. Sports illustrated Jan 11. Available from: https://www.si.com/more-sports/photos/2008/01/11-3athletesand-their-tattoos-from-a-z.

3 https://edition.cnn.com/2017/10/23/sport/gallery/sports-stars-tattoos/ index.html 
4 Cheadle H. A brief history of Tattoos in the NBA. Vice May 17, 2011 [accessed 2018 Aug 18]. Available from: https://www.vice.com/en_us/ article/8gmmm4/a-brief-history-of-tattoos-in-the-nba.

5 Tennis Europe brochure (2017) [accessed 2018 Aug 19]. Available from: http://www.tenniseurope.org/page/12173/About-Tennis-Europe.

6 Tattoo-tennis: des joueuses et des joueurs à fleur de peau. Luxemburger Wort March 20, 2014 . Available from: https://www.wort.lu/fr/ sport/tattoo-tennis-des-joueuses-et-joueurs-a-fleur-de-peau$532989 f 8 \mathrm{e} 4 \mathrm{~b} 091407 \mathrm{fd} 09035$.

7 Wohlrab S, Stahl J, Kappeler PM. Modifying the body: motivations for getting tattooed and pierced. Body Image. 2007 Mar;4(1):87-95.
8 Raspa RF, Cusack J. Psychiatric implications of tattoos. Am Fam Physician. 1990 May;41(5):1481-6.

9 Swami V, Gaughan H, Tran US, Kuhlmann T, Stieger S, Voracek M. Are tattooed adults really more aggressive and rebellious than those without tattoos? Body Image. 2015 Sep;15:149-52.

10 Bruner R. Why Wimbledon players have to wear all white. Time. July 2, 2018. Availablefrom:http://Time.com/5323876/wimbledon-2018-dresscode/.

11 Ward A. The tattooed ladies of Wimbledon: Female tennis stars muscle in by showing off their considerable collection of body art. The Daily Mail [accessed 2018 Aug 18]. Available from: http://www.dailymail.co. uk/news/article-3666921/Muscling-s-tattooed-ladies-SW19.html. 